\title{
BNCC DO ENSINO MÉDIO E TRABALHO PEDAGÓGICO DA ESCOLA: propostas da audiência pública de Brasília
}

\author{
Edileuza Fernandes Silva \\ Universidade de Brasília - UnB \\ Alessandra Valéria de Paula \\ Universidade de Brasília - UnB
}

\begin{abstract}
Resumo
A elaboração da Base Nacional Comum Curricular do Ensino Médio foi marcada por ações contraditórias entre o Estado e os atores sociais que clamam por participação nas decisões que afetam a Educação Básica no Brasil. Este artigo resulta de estudo realizado na fase de elaboração do Parecer final do texto da Base e objetiva refletir sobre as implicações da BNCC do Ensino Médio no trabalho pedagógico da escola e na construção do conhecimento. Em um contexto marcado por disputas entre os múltiplos atores socioestatais, foram organizadas audiências públicas nas cinco regiões do país como estratégia de legitimação do texto junto à sociedade civil. Nessas ocasiões as entidades participantes puderam entregar ao Conselho Nacional de Educação, notas, avaliações técnicas e moções ao texto inicial. Os dados foram levantados da observação da audiência pública de Brasília, dos documentos entregues pelas entidades e do Parecer final do relator. Os resultados revelam que a Base do Ensino Médio repercutirá no trabalho pedagógico da escola alijando a formação dos estudantes, padronizando conhecimentos, reforçando a dualidade da educação para os diferentes grupos sociais e afetando a autonomia docente, fragilizando a sua profissionalidade.
\end{abstract}

Palavras-chave: Base Nacional Comum Curricular. Ensino Médio. Trabalho pedagógico. Audiência pública.

\begin{abstract}
The drafting of the Brazilian High School Common Curriculum Base was marked by contradictory actions between the State and the social actors that claim for participation in the decisions that affect the Basic Education in Brazil. This paper is the result of a study carried out during the writing of the Final Opinion on the text of the Base and aims to consider High School BNCC implications in the pedagogic work of the school and in knowledge building. In a context marked by disputes among the several socio-state actors, public hearings have been organized in the five regions of the country, as a strategy to legitimate the text with civil society. During such meetings, participating entities delivered to the National Council of Education notes, technical assessments and motions to the final text. The data were obtained from the observation of the public hearing in Brasilia, from documents delivered by the entities and from the rapporteur's final opinion. The results demonstrate that the High School Base will affect the pedagogical work of the school, shirking the student's formation, standardizing knowledges, reinforcing the education duality for the different social groups and affecting teacher's autonomy, thus weakening their professionalism.
\end{abstract}

Keywords: Brazilian Common Curriculum Base. High School. Pedagogical work. Public hearing.

ISSN 1645-1384 (online) www.curriculosemfronteiras.org 


\section{Introdução}

Pode-se considerar que a ideia de uma base comum nacional para a Educação Básica brasileira começa a se firmar na Lei $n^{\circ} 5.692 / 71$ que definia em seu art. $4^{\circ}$ que os currículos do ensino de $1^{\circ}$ e $2^{\circ}$ graus teriam um núcleo comum, obrigatório em âmbito nacional, e uma parte diversificada para atender às especificidades locais, aos projetos das instituições de ensino e às diferenças individuais dos estudantes. Essa ideia é retomada na Lei de Diretrizes e Bases da Educação Nacional (LDBEN), de 20 de dezembro de 1996 (Lei nº 9.394/96), art. 26:

os currículos do ensino fundamental e médio devem ter uma base nacional comum, a ser complementada, em cada sistema de ensino e estabelecimento escolar, por uma parte diversificada, exigida pelas características regionais e locais da sociedade, da cultura, da economia e da clientela (BRASIL, 1996).

A postergação da definição da Base Comum Nacional da Educação Básica, prevista na LDBEN, deu-se em função da aprovação das Diretrizes Curriculares Nacionais das etapas e das modalidades de ensino, a partir dos anos 2000, período que marca o que Ciavatta e Ramos (2012) denominam "era das diretrizes".

Saviani (2016) e Frigotto (2018) asseveram que as bases deveriam ser entendidas como referências para organizar o currículo escolar e o trabalho pedagógico nas escolas a partir de direcionamentos feitos pelas diretrizes curriculares. Assim, compete às escolas a definição, em seus projetos pedagógicos, da forma como os conhecimentos científicos, historicamente acumulados pela humanidade, serão trabalhados. Para Saviani (2016), se a base comum já se encontra definida por meio das diretrizes curriculares nacionais, questiona-se o sentido da elaboração e da aprovação de uma base nacional comum curricular.

Alinhados com Saviani (2016), Craveiro e Ribeiro (2017) consideram suficientes as diretrizes curriculares e as tradições disciplinares de cada área do conhecimento para a negociação dos saberes a serem privilegiados nas redes de ensino e ressaltam a necessidade de se debater tema de tamanha relevância que afetará milhares de jovens. A definição de uma política curricular para um país tão heterogêneo, multicultural e desigual como o Brasil requer a escuta dos sujeitos diretamente envolvidos no processo educativo. Serão eles a concretizar, por meio do trabalho pedagógico intencionalmente pensado e planejado, o proposto na Base e isso não pode ocorrer à revelia dos projetos político-pedagógicos das escolas.

A ausência de diálogo com estudantes e educadores chama a atenção para a intenção do governo com a instituição de uma Base Comum Curricular, se ela estaria a serviço das escolas ou de conglomerados empresariais.

Se é para se ter uma referência que dê parâmetros para as escolas (combinando conteúdos e níveis de complexidade de desempenho), tudo bem. Se é para responsabilizar escolas, impor uma cultura padrão sobre outras culturas, punir ou premiar professores, trocar diretores, pagar bônus, credenciar professores, orientar 
grandes conglomerados empresariais a produzir material didático, privatizar, engessar a formação de professores e outras ideias já testadas em outros lugares e que destruíram por lá o sistema público de educação, então a resposta é não (FREITAS, 2015, n.p.) $)^{1}$.

A vinculação da Base às avaliações externas é outro aspecto a se destacar, tendo em vista os resultados dos testes padronizados serem usados pelo governo para justificar a Base Nacional Comum Curricular do Ensino Médio (BNCCEM). Essa vinculação da organização da educação às avaliações externas implica prejuízo pedagógico e pode interferir no trabalho dos professores, a ponto de eles darem centralidade às matrizes de referências dos testes e não ao currículo construído pelos coletivos escolares a partir de seus projetos políticopedagógicos. As determinações das avaliações externas sobre os conhecimentos aos quais os estudantes terão acesso e sobre o trabalho pedagógico reverberam no processo didático que pressupõe ensinar, aprender, avaliar em sala de aula, e dificultam o alcance dos objetivos e das intencionalidades do projeto da escola, bem como o cumprimento de sua função social.

A partir dessas considerações, neste artigo busca-se refletir sobre as implicações da BNCCEM no trabalho pedagógico da escola e na construção do conhecimento. Entende-se o trabalho pedagógico como processo intencional e planejado, que contempla as categorias: objetivos, conhecimentos, métodos, avaliação e relação pedagógica professor-aluno, com vistas ao cumprimento das finalidades educativas previstas legalmente, mas que se ampliam a partir dos objetivos e metas dos projetos pedagógicos das escolas, construídos democrática e participativamente. A escola democrática é aquela que não nega aos estudantes os níveis mais elevados do conhecimento cultural da humanidade, indispensável às classes populares menos privilegiadas (SAVIANI, 2012).

A reflexão se dará em torno das principais propostas apresentadas por representantes de entidades presentes na audiência pública da BNCCEM, realizada no Conselho Nacional de Educação (CNE), em Brasília, no dia 14 de setembro de 2018. Os dados foram levantados a partir da observação da audiência pública de Brasília, dos documentos entregues pelas entidades e do parecer final do relator.

O momento histórico da escrita deste artigo é de adequação dos currículos das redes de ensino à BNCCEM, o que impactará no trabalho pedagógico das escolas para dar materialidade ao chamado "Novo Ensino Médio". Pela reflexão, acredita-se que "a natureza dialética do real encontra, na consciência da contradição, sua expressão subjetiva, e também a possibilidade de uma interferência no real” (CURY, 1985, p. 32) como meio de resistência às reformas curriculares impostas e que representam um projeto de legitimação do processo de mercantilização que atinge a educação pública. 


\section{Base Nacional Comum Curricular: reforço à dualidade da formação dos jovens do Ensino Médio}

A BNCCEM, documento de caráter normativo que define o conjunto orgânico e progressivo de aprendizagens essenciais que todos os alunos devem alcançar (BRASIL, 2017a), é anunciada como arrojada, inovadora e asseguradora dos direitos de aprendizagem e desenvolvimento dos estudantes do Ensino Médio de escolas públicas e privadas do País. Entretanto, mesmo tendo sido aprovada em dezembro de 2018 pelo CNE, e homologada no mesmo mês pelo Ministro da Educação, permanece sem a concordância de parte significativa da sociedade, especialmente dos professores e de suas entidades representativas.

O slogan "se a base é a mesma, as oportunidades também serão" divulgado pelo Ministério da Educação (MEC) em mídias e em sua página², em 2018, tenta convencer a sociedade de que haverá igualdade de acesso ao conhecimento por todos, indistintamente. A estruturação curricular em cinco itinerários formativos, com o argumento do Estado de que haverá maiores oportunidades para o jovem construir seu "projeto de vida", coloca, no entanto, em polos distintos a continuidade de estudos na Educação Superior e a inserção no mundo do trabalho. Essa ideia é um reforço à dualidade histórica da educação brasileira caracterizada por uma educação para as elites e outra para os grupos sociais populares.

A reforma do Ensino Médio articulada à BNCCEM é um retrocesso na formação da nossa juventude porque recupera princípios previstos na Reforma Capanema, da década de 1940 (ensino secundário), e na Lei $\mathrm{n}^{\circ}$ 5.692/71, que tornou obrigatório o ensino profissionalizante para atender à necessidade de mais mão de obra no período em que o Brasil vivia o denominado "milagre econômico". Mais uma vez, para os que assumirão postos de liderança na sociedade, serão criadas as condições para a continuidade de estudos na Educação Superior e para os que serão comandados, será ofertado o ensino profissionalizante, para o qual não importa a compreensão e a apropriação dos fundamentos do fazer prático que ocorrerá desarticulado do processo produtivo (SAVIANI, 2016).

Uma base nacional curricular não deve ser entendida como currículo prescritivo de aprendizagens mínimas unificadas para a educação nacional. Apesar do vocábulo curricular em seu sintagma, o seu papel deveria ser o de garantir certa unidade curricular, sem uniformizar as propostas curriculares dos sistemas de ensino. A prescrição de mínimos supõe um projeto de cultura comum para os membros de determinada comunidade e afeta a escolaridade obrigatória dos jovens estudantes. Isso vai na contramão de uma sociedade democrática, cujo projeto educacional deve primar pela aglutinação de elementos de cultura comum que formam o consenso democrático a respeito das necessidades culturais partilhadas e essenciais dessa comunidade (SACRISTÁN, 2000). O contrário disso provoca o alijamento da formação dos jovens, retirando deles a possibilidade de apropriação do conhecimento, meio de sua humanização, e reforça a desigualdade característica da sociedade capitalista.

Nas Diretrizes Curriculares Nacionais do Ensino Médio (2018), art. 6º VIII, d: “a cultura é conceituada como processo de produção de expressões materiais, símbolos, representações e significados que correspondem a valores éticos, políticos e estéticos que orientam normas de conduta de uma sociedade” (BRASIL, 2018a). Assim, o processo de ensino-aprendizagem 
"ocorre a partir de uma cultura, para uma cultura e inserido em uma cultura, ou seja, o ensino vai muito além de aprender a ler ou a resolver expressões matemáticas de raciocínio mínimo para formar um cidadão” (STANGE, 2018). De acordo com Paro (2013), a cultura está expressa em toda ação do homem sobre a natureza. O homem, ser da natureza orgânica e inorgânica (MARX, 2004), transforma-se em um ser social e histórico ao transformar a natureza, humaniza-se e transcende a si próprio no e pelo trabalho, atividade vital e fundante do ser humano, é início e sucessão, função e continuidade (MÉSZÀROS, 2008) no processo de alimentar-se, vestir-se, habitar, enfim, manter-se vivo, reproduzir-se (MARX, 2004).

Nessa perspectiva, o trabalho é o fundamento ontológico próprio da natureza do ser social, matriz de objetivações, de realização do ser humano no desenvolvimento de suas potencialidades físicas, mentais, criativas e emocionais. Na mesma direção, o artigo $6^{\circ}$, inciso VIII, alínea "a" das DCNEM (BRASIL, 2018a), apresenta uma compreensão de trabalho "na sua perspectiva ontológica de transformação da natureza, ampliada como impulsionador do desenvolvimento cognitivo, como realização inerente ao ser humano e como mediação no processo de produção da sua existência”. Assim, essa atividade que constitui o ser social gera conhecimentos e habilidades que precisam ser universalizados por meio da educação, tendo em vista que

[...] o processo educativo é central à construção do homem em sua especificidade histórica, pois permite que não precisemos reinventar o mundo a cada nova geração, permite que conheçamos o estágio de desenvolvimento humano atual para que possamos superá-lo. (PARO, 2013, p. 42).

Nesse sentido, é inadmissível oferecer aos estudantes do Ensino Médio o acesso a mínimos necessários à produção, à execução de tarefas laborativas para a reprodução social do capital.

A sociologia do currículo ajuda a compreender as dinâmicas de reprodução, controle e resistência presentes nas políticas educacionais. Acima dos aspectos tecnicistas curriculares, existem as esferas política, econômica e cultural do contexto social presentes em um currículo oculto, expresso ideologicamente pela hegemonia de significados e práticas, na seleção, na exclusão e na diluição dos conhecimentos reproduzidos no corpus formal escolar, baseados em uma visão estratificada por classes e por critérios de "competência” (APPLE, 2006). Esses aspectos, potencializados pela exploração dos índices de reprovação dos estudantes e de desempenho das escolas expressos pelo Índice de Desenvolvimento da Educação Básica (Ideb) e por resultados do Exame Nacional do Ensino Médio (Enem), caracterizam uma parametrização do currículo escolar via avaliações em larga escala.

Ao que tudo indica, o trabalho pedagógico e curricular no Ensino Médio continuará a ser pautado pelo Enem, e não o contrário, como seria pedagogicamente coerente. Desse modo, as avaliações estandardizadas e os índices de desempenho nacionais e internacionais passam a justificar a criação de uma base comum para a última etapa da Educação Básica. Nessa perspectiva, tanto a avaliação praticada na escola quanto a externa a ela têm o condão de vaticinar quem é capaz ou não, apto ou não, apropriado ou não para acessar os 
conhecimentos clássicos produzidos pela humanidade. A avaliação volta-se à exclusão da escola de grupos sociais populares entendendo que "o que deveria ser uma diferença não essencial, que permitisse uma ação pedagógica diversificada, é elevado à categoria de contradição, na medida em que passa a ser uma 'explicação científica' para a exclusão" (FREITAS, 2002, p. 246).

Desse modo, a avaliação hierarquiza socialmente a escola e separa os que têm direito a ingressar na Educação Superior dos que recebem a formação no Ensino Médio como terminalidade e se encaminham para o mercado de trabalho. Ratifica-se, assim, a dualidade da escola, preocupação da comunidade educacional e escolar expressa em depoimentos de representantes das entidades presentes na audiência pública que será discutida a seguir.

\section{Audiência pública da BNCCEM: arena de resistências}

A audiência pública ${ }^{3}$ da região Centro-Oeste ocorreu em Brasília no dia 14 de setembro de 2018 com a participação de órgãos, entidades e associações inscritos previamente por meios eletrônicos. A audiência foi promovida pelo CNE, órgão de Estado, integrante do Ministério da Educação, composto por 24 Conselheiros, sendo doze na Câmara de Educação Básica e doze na Câmara de Educação Superior, nomeados pelo Presidente da República. O CNE tem atribuições normativas, deliberativas e de assessoramento ao ministro, instituídas pela Lei n ${ }^{\circ}$ 9.131/1995, e emite pareceres sobre matérias como a BNCC.

Em abril de 2018, o presidente Michel Temer, pela primeira vez na história do CNE, revogou o decreto de nomeação e recondução de conselheiros editado pela presidenta Dilma Rousseff. Esse ato gerou indignação de entidades educacionais expressa em nota ao $\mathrm{CNE}^{4}$, na qual se registra que "[...] a composição do CNE nas últimas décadas vinha assegurando a presença de vozes que representam coletivos de professores e pesquisadores do campo educacional comprometidos com a defesa da educação pública”. A nova configuração do Conselho compôs o conjunto de manobras do Governo Federal à época para criar as condições favoráveis à aprovação da BNCCEM, a despeito da vontade da comunidade educacional.

O auditório disponível para a audiência dispunha de apenas duzentos e quarenta lugares, o que dificultou o acesso de várias pessoas não inscritas que se aglomeraram no portão de entrada do prédio. Destaca-se que, mesmo com a existência de assentos vagos no auditório, houve impedimento da entrada de professores, o que gerou manifestações de representantes sindicais e da universidade pública. Após negociação, o presidente do CNE, Eduardo Deschamps, autorizou a entrada dos demais cidadãos. Esse fato ilustra a indisposição em se democratizar o debate acerca da temática, gerando críticas ao processo de elaboração do texto da Base.

Após iniciado o debate, uma estudante secundarista interpelou o presidente do Conselho acerca da composição da mesa diretora exclusivamente por conselheiros do sexo masculino em um colegiado composto majoritariamente por mulheres. Diante disso, o presidente passou a condução dos trabalhos para a Conselheira Márcia Aguiar. 
Representantes de associações, federações, sindicatos, institutos federais, confederações, cooperativas, sociedades, organizações estudantis e de pais/mães fizeram o uso da palavra por toda a manhã e por certo período da tarde. A maioria dos participantes se manifestou crítica e enfaticamente em um tempo máximo de três minutos, denunciando a forma antidemocrática adotada pelo governo para legitimar a reforma do Ensino Médio via BNCCEM. Falas recorrentes denunciaram as intenções mercadológicas da reforma e as consequências na formação de discentes oriundos de grupos sociais menos favorecidos economicamente. Denunciaram ainda, a interferência na autonomia docente para construir o currículo escolar e organizar o trabalho pedagógico. Alguns representantes destacaram os interesses do capital e de reformadores empresariais da educação à espreita do mercado promissor que representa a educação básica brasileira, pois 73,5\% dos alunos frequentam escolas da rede pública de ensino (CAMPOS, 2017), número considerável de possíveis clientes para os proprietários de escolas privadas.

Os temas abordados pelos participantes que tiveram direito a voz foram:

a) o financiamento estrutural para a implementação da Base;

b) o alijamento da formação com a obrigatoriedade, nos três anos do Ensino Médio, de língua portuguesa e matemática apenas;

c) a oferta dos itinerários formativos em redes de ensino que têm escolas precárias e sucateadas e/ou contam com apenas uma unidade escolar.

Quase a totalidade dos representantes defendeu a revogação da Lei ${ }^{0}$ 13.415/2017 (Reforma do Ensino Médio), a não aprovação da BNCCEM e a ampliação do debate com a participação da comunidade escolar. Na contramão da vontade popular, no entanto, apenas três dos doze conselheiros que compunham a Câmara de Educação Básica ${ }^{5}$ manifestaram-se pela revogação da Lei 13.415/2017 (BRASIL, 2017b) e pela não aprovação da Base do Ensino Médio, como expressam os excertos de três ${ }^{6}$ conselheiros:

[...] muitas escolas brasileiras nos dão exemplos de soluções educacionais [...] podemos aprender com essas escolas de uma maneira mais ampla se pudermos ouvi-las, e não apenas ouvir, mas chamá-las para o processo de coelaboração de uma nova proposta. [...] temos que revogar e devolver ao MEC, pois o CNE não pode melhorá-la. (Conselheiro 1).

[...] votamos contra a BNCC do ensino fundamental, porque discordávamos de uma série de questões. [...] o Conselho Estadual de Educação do Rio de Janeiro, do qual tenho a honra de ser presidente, não apoia a base. (Conselheira 2).

Estamos vivenciando uma reforma da educação nacional, uma reforma silenciosa, porque vem mediante modificações em várias instâncias, em várias organizações que compõem a estrutura mesmo da nossa educação e não tem sido discutida com todos os que estão diretamente interessados e os que são responsáveis por isso, [...] daí a minha posição contrária à BNCC. (Conselheira 3). 
Os demais conselheiros se restringiram a ressaltar a importância das audiências públicas, oportunidade de os diversos segmentos da sociedade contribuírem para a construção do documento em um processo democrático. Essas sessões, mesmo sem caráter deliberativo, são essenciais para a elaboração da norma que reflita o panorama educacional brasileiro. Destacam-se as falas a seguir:

Queria destacar a importância da escuta e agradecer a todas as pessoas [...]. Há contribuições bastante relevantes e dizer da importância, em que pesem todas as questões que foram colocadas a respeito de maior tempo, a importância da fala e da escuta nesta que é a última audiência pública, e ela acontecer tem significado muito grande para todos nós [...]. (Conselheira 4)

É muito gratificante poder escutar, ter essa ouvidoria a partir de que temos uma missão muito importante de fazer ajustes, de consolidar as ideias, tirar ou, enfim, acrescentar ou retirar do texto para que ele possa cumprir a sua missão [...]. (Conselheira 5)

[...] esse momento é muito raro, muito importante [...] essa abertura de um espaço de diálogo com a sociedade, mesmo que não seja possível estar nas 27 unidades da Federação e nos 5560 municípios, não podemos deixar de reconhecer o esforço deste Conselho de estar presente nas cinco regiões do País para tentar ouvir, ainda, algumas críticas, algumas sugestões e contribuições ao texto encaminhado pelo MEC (Conselheiro 6)

Como representante do Governo à época, a Conselheira quatro defendeu a Base e destacou a importância da fala e da escuta, mesmo diante de inúmeros posicionamentos contrários à Base.

Pode-se considerar que a dinâmica da audiência não respeitou o princípio democrático da participação dos sujeitos, uma vez que as propostas críticas à Base não foram acolhidas e os pedidos por mais tempo e espaço para o debate feitos pelas comunidades acadêmica, educacional e escolar presentes não foram acatados.

Há novas questões acerca desta temática de tamanha relevância para a formação dos jovens estudantes brasileiros, marcada por divergências entre a comunidade escolar e os conselheiros do CNE. A seguir, apresenta-se um quadro-síntese de propostas dos representantes de entidades ligadas à educação, entregues ao CNE na audiência pública de Brasília. Dentre os diversos temas discutidos, destacam-se os relacionados ao trabalho pedagógico das escolas, por constituírem o eixo de análise neste artigo. 
Quadro-síntese 1 - Propostas ao texto da BNCCEM que impactam o trabalho pedagógico das escolas

\begin{tabular}{|l|c|l|}
\hline \multicolumn{1}{|c|}{ Entidade } & Documento & \multicolumn{1}{|c|}{$\begin{array}{c}\text { Temas relacionados ao trabalho } \\
\text { pedagógico das escolas }\end{array}$} \\
\hline $\begin{array}{l}\text { 1. Associação Nacional pela Formação dos } \\
\text { Profissionais da Educação (Anfope) }\end{array}$ & Carta & Centralidade das avaliações de larga escala \\
\hline 2. União Marista do Brasil (Umbrasil) & Carta & $\begin{array}{l}\text { Forte vínculo com indicadores de } \\
\text { qualidade medidos por avaliações como o } \\
\text { Programa Internacional de Avaliação de } \\
\text { Alunos (Pisa) }\end{array}$ \\
\hline $\begin{array}{l}\text { 3. Associação de Geógrafos Brasileiros } \\
\text { (AGB) }\end{array}$ & Carta & $\begin{array}{l}\text { Pedagogia por competências e formação } \\
\text { flexível }\end{array}$ \\
\hline 4. Sociedade Brasileira de Física (SBF) & Carta & Prejuízo à formação científica mínima \\
\hline $\begin{array}{l}\text { 5. Federação Nacional das Escolas } \\
\text { Particulares (Fenep) }\end{array}$ & Carta & $\begin{array}{l}\text { Interferência na autonomia das escolas } \\
\text { para a construção de seus projetos } \\
\text { pedagógicos }\end{array}$ \\
\hline 6. Instituto Federal Baiano (IFB) & Relatório & Formação docente \\
\hline $\begin{array}{l}\text { 7. Sindicato dos Professores do Ensino } \\
\text { Oficial do Estado de São Paulo (Apeoesp) }\end{array}$ & $\begin{array}{l}\text { Abaixo - } \\
\text { assinado }\end{array}$ & $\begin{array}{l}\text { Educação a distância, privatização e } \\
\text { mercantilização da Educação Básica }\end{array}$ \\
\hline $\begin{array}{l}\text { 8. Sociedade Brasileira para o } \\
\text { Progresso da Ciência (SBPC) }\end{array}$ & Carta & $\begin{array}{l}\text { Fragmentação de conteúdos essenciais às } \\
\text { Ciências da Natureza e às Ciências } \\
\text { Humanas e Sociais aplicadas }\end{array}$ \\
\hline
\end{tabular}

Quadro organizado pelas autoras (2018) a partir dos arquivos disponibilizados pelo CNE. Disponíveis em: http://portal.mec.gov.br/component/content/article?id=70301_Acesso em: 26 out. 2018.

\section{As implicações da BNCCEM no trabalho pedagógico das escolas}

O trabalho pedagógico desenvolve-se na escola como um todo, por todos os profissionais e estudantes, e em sala de aula tendo como protagonistas professor e alunos. Esse trabalho é sistematizado no Projeto Político-Pedagógico (PPP) da escola, documento que deve ser acompanhado e avaliado periódica e coletivamente. O PPP contempla as categorias do trabalho pedagógico: objetivos, conteúdos, avaliação, métodos e relação pedagógica professor-aluno que, a depender do projeto defendido, podem se aliar aos interesses hegemônicos de grupos no poder e visar à manutenção das estruturas sociais dominantes; ou podem estar a serviço da transformação dos sujeitos que têm acesso à educação escolar em um processo de emancipação humana.

A partir das indicações das entidades relacionadas no quadro-síntese, foram selecionados os temas mais prementes que serão analisados com o objetivo de contribuir com o debate acerca das implicações da BNCCEM no trabalho pedagógico das escolas de Ensino Médio. 


\section{A centralidade das avaliações externas}

A vinculação da BNCCEM à política de parametrização do MEC e da Organização para a Cooperação e Desenvolvimento Econômico (OCDE), por meio do Pisa, foi preocupação evidenciada pela Anfope e pela União Marista do Brasil. A avaliação escolar cumpre a importante função de subsidiar gestores, coordenadores, professores e estudantes com informações a respeito dos desempenhos dos discentes e da escola, indica o alcance ou não dos objetivos de ensino e de aprendizagem e orienta a reorganização do trabalho pedagógico. "Na verdade o objetivo e a avaliação orientam todo o processo que se segue" (FREITAS et al., 2014, p. 15) na escola e na sala de aula.

Nesse sentido, parte-se do pressuposto de que o processo de avaliação interna da escola, por meio das avaliações de sala de aula e institucional, articulado à análise reflexiva dos resultados dos exames externos, possibilitaria aos gestores e aos professores ter referenciais que lhes ofereceriam significativas informações acerca do desempenho dos estudantes, bem como da própria escola, o que poderia contribuir para a reorganização do seu trabalho. No entanto, as avaliações de redes de ensino, pensadas para "traçar séries históricas do desempenho dos sistemas, que permitam verificar tendências ao longo do tempo, com a finalidade de reorientar políticas públicas” (FREITAS et al., 2014, p. 47) têm sido utilizadas pelos governos para ranquear estudantes e escolas. Assim, o que vemos comumente é o tensionamento causado por esses resultados com pressão sobre as escolas e a determinação externa ao seu trabalho pedagógico. Nessa perspectiva, avaliar deixa de ser um ato de diagnóstico do desempenho do estudante e de correção dos rumos da aprendizagem para servir às políticas de testes estandardizados, inseridos nas lógicas de controle, responsabilização - accountability - e meritocracia (FREITAS, 2002), sem autorreflexão individual e coletiva, desejável e necessária para se avançar na qualidade dos processos educativos.

Assim, objetivos e conteúdos ficam subalternizados à categoria avaliação, padronizada pela base comum. Essa padronização ocorre não apenas na dimensão curricular, mas também na intelectual, como assevera Pinar (2007, p. 353): "Isto significa a extinção da liberdade académica e, consequentemente, oportunidades perdidas de originalidade, criatividade, dissentimento e descoberta, a própria raison d'être das instituições educacionais”. Por consequência, essa prática leva a processos de responsabilização da comunidade escolar e passa a ser a justificativa para soluções privatizantes de consultorias empresariais para a escola.

\section{A pedagogia das competências}

A pedagogia das competências recuperada na BNCCEM é perspectiva epistemológica questionada pela Associação de Geógrafos Brasileiros (AGB), com base no entendimento de que propicia, programaticamente, uma formação flexível.

O novo Ensino Médio divide-se em Formação Geral Básica, com carga horária total máxima de 1.800 horas (60\%), em que Língua Portuguesa e Matemática são as disciplinas 
obrigatórias nos três anos dessa etapa, e Itinerários Formativos, com carga horária total mínima de 1.200 horas (40\%) organizadas em quatro eixos estruturantes (Investigação Científica, Processos Criativos, Mediação e Intervenção Sociocultural, e Empreendedorismo) para que os estudantes escolham e se aprofundem em uma ou mais áreas de conhecimento e/ou na Formação Técnica e Profissional.

No texto da Base, competência pressupõe "a mobilização de conhecimentos (conceitos e procedimentos), habilidades (práticas cognitivas e socioemocionais), atitudes e valores para resolver demandas complexas da vida cotidiana, do pleno exercício da cidadania e do mundo do trabalho” (BRASIL, 2017a, p. 8). Recupera-se na BNCCEM a pedagogia que enfatiza o que os alunos devem "saber" e "saber fazer", aprendizagens essenciais para a aquisição de competências e habilidades. Nessa perspectiva, o método se sobrepõe aos conteúdos escolares vinculados à ideia de "projeto de vida", ao alunocentrismo e à secundarização do professor na transmissão de conhecimentos, sob alegações tecnológicas de um mundo em constante mutação para atender às "exigências do século XXI". A ênfase é no "aprender a aprender" e no "aprender a fazer" (BRASIL, 2017a). Em nome da autonomia, o estudante é instado a desenvolver os próprios métodos de aquisição e descobertas em oposição à transmissão de conhecimentos científicos, elaborados e construídos pelo conjunto da humanidade. Freitas (2018, p. 83) ressalta que, "por este veio 'positivista', tudo que não for referente ao básico (Português e Matemática, no máximo Ciências) e não puder ser medido em testes fica de fora e é desestimulado".

O questionamento da representante da AGB expressa inúmeras dúvidas acerca da implementação dos itinerários formativos, principalmente em um sistema de ensino com disparidades regionais e de estrutura física das escolas. É possível que, no horizonte da implementação da política curricular, se vislumbre a proliferação de escolas terceirizadas charters -, que celebrarão contrato de gestão com o Estado para a oferta do Ensino Médio, efetivando-se, desse modo, a formação flexível, a distância e inacessível aos jovens brasileiros.

Portanto, é imperioso o acompanhamento, pelos educadores e pelas suas entidades representativas, das ações dos dirigentes dos sistemas e das redes de ensino na seleção das instituições parceiras e dos cursos a serem oferecidos via itinerários formativos.

\section{Alijamento da formação científica dos jovens}

A Sociedade Brasileira de Física (SBF) lamentou o prejuízo à formação científica mínima dos estudantes com a não obrigatoriedade de disciplinas de referência da área de Ciências da Natureza e a diminuição de sua carga horária na Base, o que poderá repercutir na exclusão de conteúdos científicos clássicos de Física, Química e Biologia. O representante da entidade asseverou que os conteúdos e os objetivos da disciplina, dispostos no texto da BNCCEM, são de difícil identificação pela comunidade estudantil e acadêmica, inclusive pelos membros da SBF. Esses não conseguiram reconhecer os tópicos de Física a serem trabalhados em sala de aula, apresentados de forma codificada nas habilidades descritas no documento. 
Na mesma direção, a Sociedade Brasileira para o Progresso da Ciência (SBPC) lamentou a ausência de conteúdo básico das disciplinas de Física, Química e Biologia e destacou que essa supressão inviabiliza as abordagens multi e interdisciplinares propostas pela BNCCEM para as áreas de Ciências da Natureza e de Ciências Humanas e Sociais aplicadas. A inexistência e/ou a fragmentação de conceitos basilares dessas áreas de conhecimento fragiliza(m) a formação científica inicial do jovem, pois "é muito pouco, em termos de um programa mínimo [...], o conjunto é muito fraco” (SBPC). Alia-se a esse fato a chance ínfima de os estudantes escolherem esses componentes não obrigatórios na formação geral básica da proposta da Base e de as escolas ofertarem os itinerários formativos dessas áreas, dada a falta de infraestrutura (laboratórios, observatórios, tecnologias digitais) e a escassez de professores.

Aprofundando a crítica, a SBF ponderou que a redução da carga horária desses componentes curriculares afeta o letramento científico mínimo e provoca a diminuição do interesse dos jovens por formação em Ciências, Engenharias, Tecnologias e Matemática (Science, Technology, Engineering, and Mathematics - STEM). Vale ressaltar que esses campos são essenciais para o desenvolvimento científico, a inovação, a ampliação dos sentidos humanos e a busca por soluções para questões técnico-científicas e econômicas do País.

Embora a BNCCEM articulada à Reforma do Ensino Médio proponha a ampliação da carga horária total dedicada ao Ensino Médio, reduziu-se o tempo destinado à formação geral básica. Segundo o artigo 35 - A, $\S 5^{\circ}$ da LDBEN de 1996, incluído pela Lei n 13.415/17, a carga horária, “destinada ao cumprimento da Base Nacional Comum Curricular, não poderá ser superior a mil e oitocentas horas do total da carga horária do ensino médio, de acordo com a definição dos sistemas de ensino”. Essa previsão se opõe às atuais duas mil e quatrocentas horas, em alguns estados, e de três mil horas ofertadas no Distrito Federal. Com a Reforma, passou-se a considerar parte da carga horária do Ensino Médio, conforme art. 17, $\S 13:$

[...], aulas, cursos, estágios, oficinas, trabalho supervisionado, atividades de extensão, pesquisa de campo, iniciação científica, aprendizagem profissional, participação em trabalhos voluntários e demais atividades com intencionalidade pedagógica orientados pelos docentes, assim como podem ser realizadas na forma presencial - mediada ou não por tecnologia - ou a distância, mediante regime de parceria com instituições previamente credenciadas pelo sistema de ensino (BRASIL, 2018a).

As Diretrizes Curriculares Nacionais para o Ensino Médio (BRASIL, 2018a) dispõem que as atividades realizadas a distância podem contemplar até $20 \%$ da carga horária total no diurno, até 30\% no noturno e até 80\% na modalidade de Educação de Jovens e Adultos. Essas práticas podem incidir tanto na formação geral básica quanto nos itinerários formativos do currículo (art. 17, § 15). Como resultado, essa forma de oferta, aliada à ênfase nos componentes Língua Portuguesa e Matemática, potencializa o encolhimento do currículo e 
representa prejuízo ao estudante em relação às demais disciplinas, o que caracteriza o alijamento da formação dos jovens.

Nesse sentido, Freitas (2002) afirma que, no interior do par dialético conteúdo/método, ocorre a objetivação da função da escola capitalista, sendo a fragmentação do conhecimento um aspecto fundamental dessa objetivação que poderá repercutir no trabalho pedagógico e na formação qualificada dos jovens do Ensino Médio.

Enquanto vislumbra-se a alfabetização científica no Ensino Fundamental como possibilidade de superação do alijamento da formação e de apropriação pelo aluno de elementos da cultura, da linguagem e dos artefatos produzidos pela ciência, essa possibilidade é reduzida para os estudantes do Ensino Médio.

\section{Autonomia da escola na construção do Projeto Político-Pedagógico}

Embora a BNCCEM não altere a prerrogativa de os entes federados, por meio dos seus sistemas de ensino e redes escolares, elaborarem e executarem suas propostas pedagógicas (art. 206, inciso I, da Constituição Federal de 1988; e art. 12, da LDBEN/1996), a Federação Nacional das Escolas Particulares (Fenep) demonstrou preocupação com a interferência na autonomia das escolas para construírem, coletivamente, seus currículos mediante os seus Projetos Político-Pedagógicos (PPP). Esse projeto é "um meio que permite potencializar o trabalho colaborativo e o compromisso com objetivos comuns [...]” (VEIGA e FERNANDES SILVA, 2018, p. 51). Sua concretização requer autonomia dos que o elaboram, no sentido de valorizar os processos e as práticas instituintes e de romper com orientações externas que visam uniformizar e negar as decisões coletivas da escola.

A preocupação manifestada pela Fenep pode ser explicada pelo fato de um currículo prescrito resultar de decisões políticas e administrativas influenciadas por interesses econômicos e políticos e por concepções que nem sempre refletem as decisões e as concepções das escolas. Em contraposição a essa lógica, o currículo deve considerar a construção do conhecimento em articulação com a realidade global e local e a sua relação com o mundo do trabalho que supere a mera reprodução dos processos produtivos e a internalização das formas de exploração do trabalho na sociedade capitalista. A perspectiva deve ser de entendimento dos aspectos políticos, econômicos e sociais e dos processos produtivos.

Uma base comum de referência obrigatória de aprendizagens essenciais, inspirada em experiências centralizadoras de currículo, pode repercutir no trabalho pedagógico da escola e do professor em sala de aula. Para lidar com essa questão, as coordenações pedagógicas coletivas nas escolas constituem espaços que podem apontar perspectivas de fortalecimento de ações reflexivas, de trabalho colaborativo entre pares e de reforço e legitimação de novas práticas na materialização do currículo em consonância com o PPP da escola. 


\section{Formação específica para a docência}

O Instituto Federal Baiano (IFB) destacou a preocupação com a flexibilização de formação específica e pedagógica para o exercício da docência no Ensino Médio, a partir da prerrogativa de contratação de professores por notório saber (LDBEN, 1996, art. 61, inciso IV), incluído pela Lei $n^{0} 13.415 / 2017$, para atender à formação técnica e profissional nos itinerários formativos. Ao subverter o sentido original do "notório saber", que consistia em medida excepcional para o reconhecimento público de conhecimento e erudição para professores da Educação Superior, e propor a certificação de conhecimento para professores da Educação Básica, o Estado se exime de sua responsabilidade precípua na formação e na valorização da carreira docente. Isso demonstra o descaso do Estado com a Educação Básica e a formação dos jovens e caracteriza mais uma medida paliativa que não resolve o real problema da formação de professores. Ainda hoje há professores leigos e precarizados desenvolvendo trabalho pedagógico na Educação Básica, e apenas 55,6\% dos docentes do Ensino Médio têm formação superior na área em que lecionam ${ }^{7}$.

Com essa medida, é possível um aluno optar por cursar o itinerário de formação técnica e profissional na modalidade normal, ser formado por um profissional com "notório saber" e estar apto a ser professor na Educação Infantil e nos cinco primeiros anos do ensino fundamental (Lei n. 13.415/2017, art. $7^{\circ}$ ). Essa prática é completamente diversa da realizada em países que verdadeiramente priorizam a educação e reservam aos professores mais bem qualificados, mestres e doutores, essas etapas da Educação Básica.

Esse aviltamento é intensificado com a introdução de plataformas instrucionais digitais, nas quais professores especialistas transmitem o conteúdo, a partir de estúdios, aos estudantes e professores que acabam se tornando meros executores, o que compromete a sua profissionalidade docente. A ênfase passa a ser nos métodos e nas práticas de ensino e não mais nos conhecimentos elaborados e construídos cientificamente e nas aprendizagens.

Enquanto isso ocorre, acompanha-se o sucateamento das universidades, desconsiderando-se alternativas viáveis para enfrentar os problemas de formação docente no Brasil, como investir em políticas de fortalecimento dos programas de graduação, pósgraduação e de cursos de formação continuada de professores em serviço.

\section{Educação a distância, privatização e mercantilização da Educação Básica}

O cumprimento do Ensino Médio a distância é objeto da discussão do Sindicato dos Professores do Ensino Oficial do Estado de São Paulo (Apeoesp) no abaixo-assinado apresentado. O Sindicato advertiu acerca das inúmeras certificações de qualidade duvidosa que podem ser oferecidas por centros ocupacionais, instituições nacionais e internacionais de trabalho supervisionado e/ou voluntário desatrelados dos princípios de formação escolar. Essas práticas ensejam a inserção da educação pública no livre mercado e a consagração das escolas charters, privatizadas via terceirização, do Ensino Médio. Para a Educação Infantil e o Ensino Fundamental, a modalidade de vouchers, na qual o Estado oferece um "cheque- 
educação" para os pais escolherem a escola privada que desejam para seus filhos, tem sido adotada por algumas redes de ensino, especialmente na Educação Infantil, para amenizar a pressão social por vagas. Assim, gradativamente, caminha-se para a extinção da educação pública, direito fundamental do cidadão e da cidadã.

Mais uma vez, o mercado dita as regras e lucra bilhões com a reforma da educação, devido ao redirecionamento dos investimentos em materiais didáticos, cursos de formação, consultorias, assessorias e repasse de recursos destinados à educação pública aos conglomerados empresariais. Como sustenta Freitas (2018),

[...] não parece que estejamos apenas frente a uma demanda por uma "nova gestão pública", ou por um "quase mercado", mas frente a uma demanda de inserção da atividade educacional no livre mercado pleno, o que equivale a promover a destruição do sistema educacional público e do controle estatal (regulação) das escolas - incluindo eliminar seus sistemas de gestão democrática -, os quais seriam, nessa visão, os responsáveis por impedir o livre funcionamento das leis de mercado em ambiente educacional (FREITAS, 2018, p. 54).

Na mesma linha, Veiga e Fernandes Silva (2018, p. 59) argumentam pela importância de envolvimento dos profissionais da educação e da comunidade escolar e de apropriação dos instrumentos existentes dizendo que "não podemos abrir mão da gestão democrática, do projeto pedagógico e do currículo, tripé imprescindível para a construção da escola voltada para a democratização do acesso, da garantia, da permanência e da qualidade”.

Nesse sentido, destaca-se que as compreensões das entidades evidenciadas nos documentos apresentados coadunam com o posicionamento do relator do processo, constantes de sua Declaração de Voto $^{8}$. O Conselheiro questionou sobre conhecimentos e habilidades, atitudes e valores a que os estudantes têm direito, observando que é na interação, entre si e com seus professores, que os estudantes desenvolvem atitudes e capacidade de convivência, além de incorporarem valores, “[...] o que exclui o uso de pedagogias centradas no ensino à distância, com o sentido atribuído a este conceito no debate educacional brasileiro atual” (BRASIL, 2018b, p. 14).

Para o relator do Parecer, a definição dos conhecimentos e das habilidades deve:

[...] expressar um equilíbrio entre a necessidade de o jovem compreender os problemas da sociedade e obter subsídios para suas decisões pessoais e cidadãs e, por outro lado, habilitá-lo ao prosseguimento dos estudos em uma área, onde participará da produção das soluções e inovações necessárias. O texto posto em votação não responde a estas necessidades (BRASIL, 2018b, p. 14).

Assim, o conselheiro encerra sua declaração reconhecendo que o dissenso faz parte do debate acadêmico e social, que ter uma posição divergente da maioria é uma forma digna de participar do debate: "Não consegui convencer os colegas dos riscos educacionais e sociais que vi na solução por eles advogada para o ensino médio, nem me convencer que estes riscos não existem. Por isso dei o meu voto contra” (BRASIL, 2018b, p. 15). 
A aprovação da BNCCEM pela Comissão Bicameral/Conselho Pleno do CNE ocorreu três meses após a última audiência pública realizada em Brasília. Para isso foram utilizados mecanismos como a substituição e a recondução de conselheiros para construir as condições objetivas favoráveis ao texto do governo federal, revelando um projeto educacional pautado pela reprodução de uma ordem que prima pela seleção do conhecimento a ser transmitido aos estudantes constituintes de grupos populares, pelo alijamento de sua formação e pela manipulação ideológica das consciências.

\section{Considerações finais}

Este artigo apresentou as questões mais prementes relacionadas à organização do trabalho pedagógico assinaladas nos documentos entregues ao CNE pelas entidades científicas, educacionais, de formação profissional e de classe presentes na audiência pública da região Centro-Oeste, realizada em Brasília no dia 14 de setembro de 2018.

As audiências públicas realizadas em Florianópolis (11/05/2018), Fortaleza (05/07/2018) e Brasília (14/09/2018), assim como, as previstas, porém canceladas em São Paulo $(08 / 06 / 2018)^{9}$ e no Pará $(10 / 08 / 2018)^{10}$, em virtude de manifestações de entidades acadêmicas, sindicais e estudantis contrárias à proposta do MEC, demonstraram a complexidade do tema e o açodamento para a aprovação das reformas para o Ensino Médio apresentadas pelo Governo Federal. Ressalta-se, no entanto, que, com a aprovação da BNCCEM, pesquisas são necessárias para se discutir e encontrar alternativas didáticometodológicas viáveis no que concerne à reformulação dos currículos escolares no âmbito dos sistemas, das redes de ensino e das escolas; à formação docente, pois a proposta da Base confronta a Resolução CNE/CP $n^{0} 2$, de $1^{\circ}$ de julho de 2015; à atualização de livros e de materiais didáticos; aos investimentos em infraestrutura e construção das escolas de Ensino Médio, uma vez que, das 181.939 escolas de Educação Básica do país, apenas 28.673 $(15,8 \%)$ ofertam essa etapa ${ }^{11}$.

Há, portanto, muito o que dialogar acerca desta temática de tamanha relevância para a sociedade, marcada por divergências entre Governo, comunidade escolar e CNE. Desse modo, a aprovação da BNCCEM em 2018 reflete e impacta o próprio modelo políticoideológico de nação e de escola; e diz sobre o governo e a governança no exercício do poder frente às demandas sociais, à agenda estatal e à comunidade escolar. Há consenso de que a discussão de medidas tão complexas exige maior tempo e espaço para a qualificação dos dissensos.

Diante disso, reconhecem-se os desafios que somente serão superados com clareza política e adesão aos instrumentos de construção coletiva assentados na gestão democrática e na decisão de participar de um projeto educacional mais justo, democrático, laico, público, inclusivo, equânime e de qualidade para todos. 


\section{Notas}

1. Publicado no Blog do Freitas em: 18/09/2015. Disponível em: https://avaliacaoeducacional.com/2015/09/18/politicaeducacional-e-base-nacional-final-2/. Acesso em: 26 ago. 2018.

2. Disponível em: http://www.mec.gov.br/. Acesso em: 11 set. 2017.

3. As autoras deste texto participaram da audiência pública realizada no Auditório do Conselho Nacional de Educação (CNE) em Brasília, no dia 14 set. 2018.

4. Nota das Entidades Educacionais ao CNE e de agradecimento a Marcia Angela Aguiar e Malvina Tuttman 08/10/2018. Disponível em: http://www.anped.org.br/news/nota-das-entidades-educacionais-ao-cne-e-de-agradecimento-marciaangela-aguiar-e-malvina. Acesso em: 17 dez. 2018.

5. Vídeo da audiência pública disponível em: www.portal.mec.gov.br. Acesso em: 15 set. 2018.

6. Conselheiros não reconduzidos ao cargo, desligados do CNE em outubro de 2018.

7. Informações disponíveis em: http://www.observatoriodopne.org.br/home/15/42/\#a-plataforma. Acesso em: 9 maio 2019.

8. Parecer CNE/CEB n ${ }^{\circ}$ 3/2018 (BRASIL, 2018b).

9. BOEHM, Camila. Audiência sobre currículo do ensino médio é suspensa após manifestação. Agência Brasil, São Paulo, 8 jun. 2018. Disponível em: http://agenciabrasil.ebc.com.br/educacao/noticia/2018-06/audiencia-sobre-curriculo-doensino-medio-e-cancela-apos-manifestacoes. Acesso em: 12 jun. 2018.

10. Nota sobre audiência pública da BNCC em Belém. Disponível em: http://www.anped.org.br/news/nota-sobre-audienciapublica-da-bncc-em-belem. Acesso em: 18 ago. 2018.

11. De acordo com o censo (2018). Disponível em: http://portal.inep.gov.br/artigo//asset_publisher/B4AQV9zFY7Bv/ content/dados-do-censo escolar-noventa-e-cinco-por-cento-das-escolas-de-ensino-medio-tem-acesso-a-internet-masapenas-44-tem-laboratorio-de-ciencias/21206. Acesso em: 27 jul. 2018.

\section{Referências}

APPLE, Michael W. Ideologia e Currículo. Porto Alegre: Artmed, 2006.

ASSOCIAÇÃO DE GEÓGRAFOS BRASILEIROS (AGB). Carta ao Conselho Nacional de Educação. Brasília, DF, 14 set. 2018. Disponível em: http//portal.mec.gov.br/component/content/article?id=70301. Acesso em: 26 out. 2018.

ASSOCIAÇÃO NACIONAL PELA FORMAÇÃO DOS PROFISSIONAIS DA EDUCAÇÃO (Anfope). Carta ao Conselho Nacional de Educação. Brasília, DF, 14 set. 2018. Disponível em: http//portal.mec.gov.br/component/content/article?id=70301. Acesso em: 26 out. 2018.

BRASIL. Base Nacional Comum Curricular: Ensino Médio. Diário Oficial da União: República Federativa do Brasil: seção: 1, Brasília, DF, ano 155, p. 146, 21 dez. 2017a.

BRASIL. Constituição da República Federativa do Brasil de 1988. Diário Oficial da União: República Federativa do Brasil: seção 1, p. 1, 5 out. 1988.

BRASIL. Lei n ${ }^{\circ}$ 5.692, de 11 de agosto de 1971. Fixa Diretrizes e Bases para o ensino de $1^{\circ}$ e $2^{\circ}$ graus. Diário Oficial da União: seção 1, Brasília, DF, p. 6377, 12 ago. 1971.

BRASIL. Lei no 9.131, de 24 de novembro de 1995. Altera os dispositivos da Lei ${ }^{\circ} 4.024$, de 20 de dezembro de 1961 e dá outras providências. Diário Oficial da União: seção 1 - Edição Extra, Brasília, DF, p. 19257, 25 nov. 1995.

BRASIL. Lei n 9.394, de 20 de dezembro de 1996. Lei de Diretrizes e Bases da Educação Nacional. Diário Oficial da União: seção 1, Brasília, DF, ano 139, nº 8, p. 27833, 23 dez. 1996.

BRASIL. Lei $n^{0} 13.415$, de 16 de fevereiro de 2017. Altera as Leis $n^{\text {os }} 9.394$, de 20 de dezembro de 1996, que estabelece as diretrizes e bases da educação nacional; e 11.494, de 20 de junho 2007, que regulamenta o 
Fundo de Manutenção e Desenvolvimento da Educação Básica e de Valorização dos Profissionais da Educação; a Consolidação das Leis do Trabalho (CLT), aprovada pelo Decreto-Lei $n^{0} 5.452$, de $1^{\circ}$ de maio de 1943; e o Decreto-Lei $n^{0}$ 236, de 28 de fevereiro de 1967; revoga a Lei ${ }^{0}$ 11.161, de 5 de agosto de 2005; e instituiu a Política de Fomento à Implementação de Escolas de Ensino Médio em Tempo Integral. Diário Oficial da União: seção 1, Brasília, DF, p. 1, 17 fev. 2017b.

BRASIL. Ministério da Educação. Conselho Nacional de Educação. Diretrizes Curriculares Nacionais para o Ensino Médio. Atualiza as Diretrizes Curriculares Nacionais para o Ensino Médio. Conselho Nacional de Educação/Câmara de Educação Básica n 3/2018. Diário Oficial da União: República Federativa do Brasil: edição: 224, seção: 1, Brasília, DF, p. 21, 22 nov. 2018a.

BRASIL. Ministério da Educação. Conselho Nacional de Educação. Resolução CNE/CP nº 2, de $1^{\circ}$ de julho de 2015. Define as Diretrizes Curriculares Nacionais para a formação inicial em nível superior (cursos de licenciatura, cursos de formação pedagógica para graduados e cursos de segunda licenciatura) e para a formação continuada. Diário Oficial da União: República Federativa do Brasil: edição: 124, seção: 1, Brasília, DF, p. 8-12, 2 jul. 2015.

BRASIL. Ministério da Educação. Conselho Nacional de Educação. Resolução CNE/CEB nº 3, de 8 de novembro de 2018. Atualiza as Diretrizes Curriculares Nacionais para o Ensino Médio, observadas as alterações introduzidas na LDB pela Lei n 13.415/2017. Diário Oficial da União: República Federativa do Brasil: seção 1, Brasília, DF, p. 49, 21 nov. 2018b.

CAMPOS, Ana Cristina. Ensino básico tem 73,5\% dos alunos em escolas públicas, diz IBGE. Agência Brasil, Rio de Janeiro, 21 dez. 2017. Disponível em: http://agenciabrasil.ebc.com.br/educacao/noticia/201712/ensino-basico-tem-735-dos-alunos-em-escolas-publicas-diz-ibge. Acesso em: 5 ago. 2018.

CIAVATTA, Maria; RAMOS, Marise A “era das diretrizes”: a disputa pelo projeto de educação dos mais pobres. Revista Brasileira de Educação, Rio de Janeiro, v. 17, n. 49, p. 11-38, jan./abr. 2012.

CRAVEIRO, Clarissa Bastos; RIBEIRO, William Goes. Precisamos de uma Base Nacional Comum Curricular? Revista Linhas Críticas, Brasília, v. 23, n. 50, p. 51-68, fev./maio 2017.

CURY, Carlos Roberto J. Educação e contradição: elementos metodológicos para uma teoria crítica do fenômeno educativo. São Paulo: Cortez, Autores Associados, 1985.

FEDERAÇÃO NACIONAL DAS ESCOLAS PARTICULARES (Fenep). Carta ao Conselho Nacional de Educação. $\quad$ Brasília, $\quad$ DF, $14 \quad$ set. $2018 . \quad$ Disponível http//portal.mec.gov.br/component/content/article?id=70301. Acesso em: 26 out. 2018.

FREITAS, Luiz Carlos. A reforma empresarial da educação: nova direita, velhas ideias. $1^{a}$ ed. São Paulo: Expressão Popular, 2018.

FREITAS, Luiz Carlos. Crítica da Organização do Trabalho Pedagógico e da Didática. São Paulo: Papirus, 2002.

FREITAS, Luiz Carlos. Política Educacional e Base Nacional - final. Avaliação Educacional - Blog do Freitas, publicado em 18 set. 2015. Disponível em: https://avaliacaoeducacional.com/2015/09/18/politicaeducacional-e-base-nacional-final-2/. Acesso em: 14 nov. 2015.

FREITAS, Luiz Carlos. et al. Avaliação Educacional: caminhando na contramão. $7^{a}$ ed. Petrópolis, Rio de Janeiro: Vozes, 2014.

FRIGOTTO, Gaudêncio. A educação está nocauteada. [Entrevista cedida a] André Antunes. EPSJV/Fiocruz. São Paulo, 15 de junho de 2018, 11h31. Disponível em: http://www.epsjv.fiocruz.br/noticias/entrevista/aeducacao-esta-nocauteada. Acesso em: 17 set. 2018.

INSTITUTO FEDERAL BAIANO (IFB). Relatório ao Conselho Nacional de Educação. Brasília, DF, 14/09/2018. Disponível em: http//portal.mec.gov.br/component/content/article?id=70301. Acesso em: 26 out. 2018.

MARX, Karl. Manuscritos econômico-filosóficos. Tradução Jesus Ranieri. São Paulo: Boitempo, 2004. 
MÉSZÀROS, István. A educação para além do capital. 2. ed. Tradução Isa Tavares. São Paulo: Boitempo, 2008.

PARO, Vitor Henrique. A teoria do valor em Marx e a educação. São Paulo: Cortez, 2013.

PINAR, William F. O que é a Teoria do Currículo? Porto, Portugal: Porto Editora, 2007.

SACRISTÁN, J. Gimeno. O currículo: uma reflexão sobre a prática. 3. ed. Tradução Ernani F. da F. Rosa. Porto Alegre: ArtMed, 2000.

SAVIANI, Dermeval. Educação escolar, currículo e sociedade: o problema da Base Nacional Comum Curricular. Revista Movimento - revista de educação, Rio de Janeiro, ano 3, n. 4, p. 54-84, 2016.

SAVIANI, Dermeval. Escola e Democracia. Campinas: Autores Associados, 2012.

SINDICATO DOS PROFESSORES DO ENSINO OFICIAL DO ESTADO DE SÃO PAULO (Apeoesp). Abaixo-assinado ao Conselho Nacional de Educação. Brasília, DF, 14/09/2018. Disponível em: http//portal.mec.gov.br/component/content/article?id=70301. Acesso em: 26 out. 2018.

SOCIEDADE BRASILEIRA DE FÍSICA (SBF). Carta ao Conselho Nacional de Educação. Brasília, DF, 14 set. 2018. Disponível em: http//portal.mec.gov.br/component/content/article?id=70301. Acesso em: 26 out. 2018.

SOCIEDADE BRASILEIRA PARA O PROGRESSO DA CIÊNCIA (SBPC). Carta ao Conselho Nacional de Educação. Brasília, DF, 14 set. 2018. Disponível em: http//portal.mec.gov.br/component/content/article?id=70301. Acesso em: 26 out. 2018.

STANGE, Carlos Eduardo B. Reflexões sobre avaliação: da concepção à ideia de sistema. In: CARVALHO, M. E. (org.). Diálogos sobre a Educação: $3^{\text {a }}$ Conae. Brasília/DF: FNE/CONAE, 2018. p. 103 -113.

UNIÃO MARISTA DO BRASIL (Umbrasil). Carta ao Conselho Nacional de Educação. Brasília, DF, 14/09/2018. Disponível em: http//portal.mec.gov.br/component/content/article?id=70301. Acesso em: 26 out. 2018.

VEIGA, Ilma Passos A.; FERNANDES SILVA, Edileuza. Ensino Fundamental: Gestão democrática, projeto político-pedagógico e currículo em busca da qualidade. In: VEIGA, I. P. A; FERNANDES SILVA, E.(org.) Ensino Fundamental: Da LDB à BNCC. Campinas, SP: Papirus, 2018.

\section{Correspondência}

Edileuza Fernandes Silva: Doutora em Educação. Professora Adjunta da Faculdade de Educação da UnB e do Programa de Pós-Graduação em Educação na Linha Profissão Docente, Currículo e Avaliação PPGE/FE/UnB. Líder do Grupo de Pesquisa e Estudos sobre Docência, Didática e Trabalho Pedagógico - PRODOCÊNCIA.

Email: edileuzafeunb@gmail.com

Alessandra Valéria de Paula: Graduada em Letras Português/Inglês, professora da Secretaria de Estado de Educação do Distrito Federal, mestranda em Educação pela Universidade de Brasília/UnB e membro do Grupo de Pesquisa Currículo e Processo Formativo: inovação e interdisciplinaridade.

Email:alevpaula@gmail.com

Texto publicado em Currículo sem Fronteiras com autorização das autoras 